\title{
Yield optimization and surface image-based strength prediction of beech
}

\author{
A. Khaloian Sarnaghi ${ }^{1}$ A. Rais ${ }^{1,2} \cdot$ A. Kovryga' ${ }^{1}$ W. F. Gard ${ }^{3}$ J. W. G. van de Kuilen ${ }^{1,3}$
}

Received: 24 September 2019 / Published online: 20 July 2020

(c) The Author(s) 2020

\begin{abstract}
Samples of European beech (Fagus sylvatica) were used for this study. Logs of these samples covered a scatter of mild-tostrong curvatures and the boards of these samples covered strong fiber deviations. This study consists of two separate parts: (1) log reconstruction and optimization of the cutting pattern, and (2) board reconstruction and strength prediction. Information about the internal quality of the logs is missing in this study, as laser scanning has been used for surface reconstruction of logs. Therefore, two separate steps were implemented here. (1) Influence of cutting pattern and board-dimensions on yield were analyzed. For this step, $50 \mathrm{logs}$ were checked. (2) A more advanced numerical method based on the finite element (FE) analysis was developed to improve the accuracy of tensile strength predictions. This step was performed, because visual grading parameters were relatively weak predictors for tensile strength of these samples. In total, 200 beech boards were analyzed in this step. However, due to the geometrical configuration of some knots, the reconstruction and numerical strength prediction of 194 boards out of 200 boards were possible. By performing tensile tests numerically, stress concentration factors (SCFs) were derived, considering the average and maximum stresses around the imperfections. SCFs in combination with the longitudinal stress wave velocity were the numerical identifying parameters (IPs), used in the nonlinear regression model for tensile strength prediction. The influence of the combination of different numerical parameters in the developed non-linear model on improving the quality of the strength prediction was analyzed. For this reason, improvement of coefficient of determination $\left(\mathrm{R}^{2}\right)$ after adding each parameter to the multiple regression analysis was checked. Performance of the developed numerical method was compared to the typical grading approaches [using knottiness and the dynamic $\mathrm{MoE}\left(\mathrm{MoE}_{\mathrm{dyn}}\right)$ ], and it was shown that the coefficient of determination is higher, when using the virtual methods for tensile strength predictions.
\end{abstract}

\section{Introduction}

Due to increased availability of beech in central Europe, as well as its higher mechanical properties, the interest in the usage of this species for structural applications is increasing (Kovryga et al. 2019). It should be noted that beech logs have generally strong frequent curvatures that affect their yield. Therefore, the aim of this study was to initially optimize the yield of the straight boards out of shorter logs, and to predict the tensile strength of the beech boards later.

A. Khaloian Sarnaghi

sarnaghi@hfm.tum.de

1 Department of Wood Technology, Technical University of Munich, 80797 Munich, Germany

2 Chair of Forest Growth and Yield Science, Technical University of Munich, 85354 Freising, Germany

3 Faculty of Civil Engineering and Geosciences, Delft University of Technology, Delft, Netherlands
Therefore, two separate numerical/modelling steps were the focus of this study, giving us the opportunity: (1) to reconstruct and analyse the beech logs with frequent curvatures and to predict the yield of these $\log$ s based on point clouds from the laser scans (showing their geometrical configurations), and (2) to reconstruct beech boards with detailed consideration of the knots on the basis of their surface images and to predict the tensile strength. Measured available data for the first step includes data of the laser scanning, actual yield and the number/size of the boards from the logs. The data for the second step of this study includes the board size, knot data, dynamic/static MoE, density, and the actual tensile strength. As laser scans provided only the surface information of the logs, linkage between these two steps could not be completed here. Therefore, the objective of the first step is the yield optimization in highly curved beech logs and the objective of the second step is numerical strength prediction of highly heterogeneous beech boards. With scanning technologies, such as Goldeneye machines of Microtec, 
which are providing the volumetric information of the logs, the process could be completed in the future.

In case of the log reconstruction (first step of this study), 3D X-ray and 3D laser log shape scanning are making it possible to analyze the surface, as well as its internal features. This allows extracting the optimized yield of the logs to categorize timber boards for different applications. Internal features in logs, such as knots and cracks and their effects on yield have been studied previously (Steele et al. 1993; Bhandakar et al. 2006; Boukadida et al. 2012). Additionally, an automatic algorithm was provided for the geometrical recognition of the knots (Longuetaud et al. 2004, 2012). Therefore, logs with strong geometrical non-uniformities can be reconstructed to predict the yield and to reduce the waste of the material for engineering applications. In case of the board reconstruction (second step of this study), consideration of the natural features with their comprehensive geometrical representation including the angle of rotation, shape and the coordinate directions in the bulk material helps for better strength predictions. These natural features (knots) influence the fiber pattern in wood, which correspondingly affect the global stiffness direction along the boards and finally the strength of the material. As knots are the main strength governing parameters, numerical methods with more accurate geometrical reconstruction of the knots may be an alternative method to improve the strength prediction of the material. Different studies focused on the structural modelling of wood and predicting the strength reduction and failure, resulting from structural non-uniformities (Goodman and Bodig 1980; Phillips et al. 1981; Cramer and Goodman 1986; Foley 2001; Baño et al. 2010; Jenkel and Kaliske 2013; Hackspiel et al. 2014; Lukacevic and Füssl 2014). The basis of most of these models is a 2D flow-grain analogy (Goodman and Bodig 1978; Foley 2001), which is extended for the 3D case here to also consider the vector component in the third direction (Khaloian et al. 2017).

As higher stresses are developing around the geometrical non-uniformities, stress concentration factors around knots (Khaloian and Van de Kuilen 2019a) as well as the stress wave velocity in the boards (Khaloian and Van de Kuilen 2019c) are multiple parameters that are used in this study for prediction of the strength of beech boards. These are the main parameters that are influenced by the natural features in timber. Small and linear dislocation of the elements due to the small impact of the stress wave, especially over the knot boundaries, is the main reason for reduction in the velocity of the wave, when traveling forth and back through the board.

The objective of this study was to analyze beech samples covering the following yield-related aspects:

(1) Analyzing beech logs: influence of the dimension of the boards and curvature of the logs on yield
(2) Prediction of strength for highly heterogeneous lowquality beech boards

\section{Materials and methods}

\subsection{General}

European beech (Fagus sylvatica) was used for this study. The experimental plots were located in the low mountain region Spessart in the north of Bavaria. In total, 16 different stands in two different Bavarian forest enterprises were selected. Altogether, 100 sampled beech trees were equally allocated to one of the five following stand types: pure beech stand and mixed stands of beech with Douglas-fir, Norway spruce, oak and pine. In total, 50 logs among the 100 sampled beech trees were randomly selected for the numerical analysis. The age of the sampled trees ranged from 44 to 174 years (Rais et al. 2020).

The site conditions were assumed to be constant, as the source rocks were sandstone of similar properties and these rocks developed to brown earths. In the same way, climate conditions with temperature and precipitation were also assumed similar for all stands.

The logs were sawn to boards when the top diameter was at least about $230 \mathrm{~mm}$ without bark. Logs were sawn using a band saw. The cutting pattern was optimized to get as many center-boards as possible with the preferred cross-section of $50 \mathrm{~mm} \times 150 \mathrm{~mm}$. From the outer parts of the stems, side boards of smaller cross-section $(40 \mathrm{~mm} \times 80 \mathrm{~mm})$ were cut out (Rais et al. 2018).

The roundwood was scanned with a Riegl LMS-Z420i laser scanning system. The $50 \operatorname{logs}$ of $4.1 \mathrm{~m}$ length that were also reconstructed in this study covered diameters between 250 and $660 \mathrm{~mm}$. The shapes of the logs were covering a scatter, including logs with strong frequent curvatures in different coordinate directions (shown in Fig. 1), and the ones with relatively straight shapes.

In the second step of this study, the boards were geometrically reconstructed by considering the influence of knots for tensile strength predictions. In total, 200 lower quality beech boards from Central Germany with up to 22 knots were used for the numerical analysis in this step. However, due to the poor geometry of 6 boards out of 200 (e.g., due to the geometrical shape of some of the knots), the reconstruction and strength prediction of 194 boards were possible numerically.

The boards came from a lower quality grade of sawn timber from Pollmeier sawmill, and they included pith, strong fiber deviations, growth defects and knots. The boards were not taken from the logs explained in the first part of the project. All beech boards that were numerically reconstructed in this study, were physically tested in tension (EN 408 2010). The strength results of the experiments (presented as 

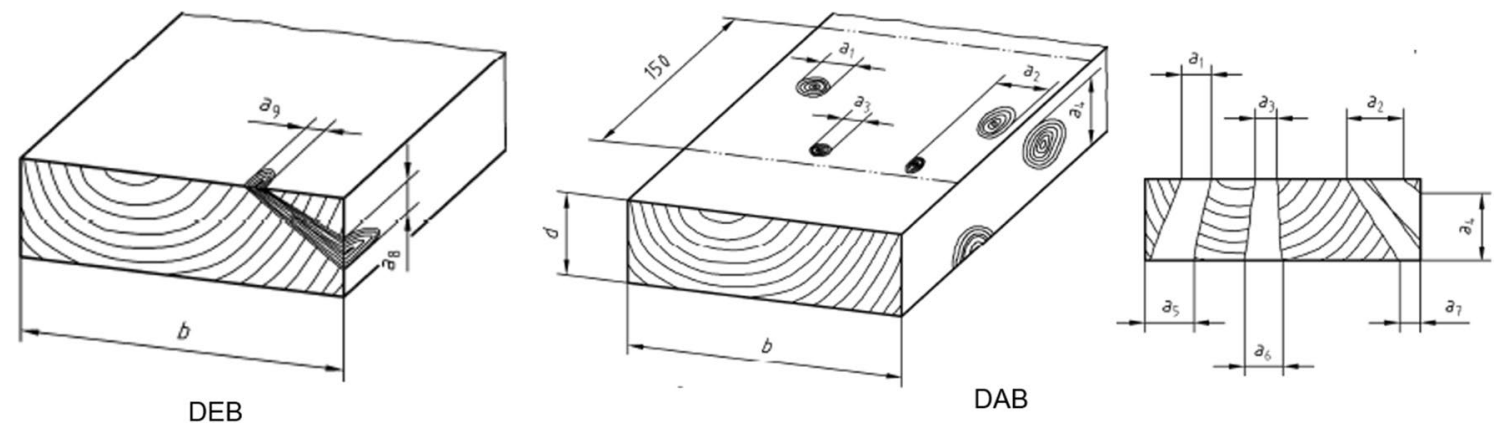

DAB

Fig. 1 Schematic representation for calculation of DEB and DAB (DIN 4074 2012)

average in Table 1) were used for validation of the model. Two sets of beech boards were considered here, which were categorized by their dimensions (presented as Beech $_{1}$ (wider one) and $\mathrm{Beech}_{2}$ in Table 1). Additionally, the visual grading parameters (DEB: single knot or DIN Einzellast Brett and DAB: knot cluster or DIN Astansammlung Brett) were calculated, which are provided in an average form in Table 1. These parameters represent the knot parameters and were used for validation of the results of virtual knot measurements. DEB and DAB parameters are presented in Eq. 1 and Fig. 1.

$D E B=\max \left[\frac{\sum a_{i}}{2 . b}\right] \quad D A B=\max \left[\frac{\sum a_{i, \text { window }}}{2 . b}\right]$

DEB was calculated by summing up the length of all the edges of knots $\left(a_{i}\right)$ that appeared over the surfaces of the board with a width of $b$ (DIN 4074 2012). DAB was calculated by summing up the edges of the projected areas of the knots, after minimizing the overlapping edges in a moving window of $150 \mathrm{~mm}$ over the board (DIN 4074 2012).

Knots and fibre deviations are the prime causes for the irregular strength profile of wood. Due to their presence, the stress distribution and the stress wave velocity get disturbed in boards. By considering single and multiple effects of the maximum and average stresses that develop around the knots, stress concentration factors $\left(\mathrm{SCF}_{\mathrm{i}}\right)$ were derived (Eq. 2). The $\mathrm{SCF}_{\mathrm{i}}$, as well as the velocity of the stress wave after passing through cross section areas with knots create the four material parameters that were introduced to predict the strength of the material by computation (Khaloian and Van de Kuilen 2019a, b, c). These four parameters include three SCFs and the simulated dynamic MoE.

$$
\begin{gathered}
S C F_{1}=\max \left(\sigma_{\text {sim }} \cdot \frac{A_{\text {knot }}}{A_{\text {total }}}\right) \quad S C F_{2}=\sigma_{\text {avg }} \cdot\left(\frac{A_{\text {total }}}{A_{\text {total }}-A_{\text {knot }}}\right) \\
S C F_{3}=\sigma_{\text {avg }} \cdot\left(\frac{A_{\text {total }}}{\left|A_{\text {total }}-A_{\text {projected }}\right|}\right)
\end{gathered}
$$

In Eq. 2, $\sigma_{\text {sim }}$ is the maximum stress around each knot. This stress is maximum $\sigma_{11}$ of the elements, in a window from the beginning to the end of each knot separately. The nominal stress $\left(\sigma_{\text {nom }}\right)$ of $1 \mathrm{MPa}$ is applied to each board. $\mathrm{A}_{\text {knot }}$ is the biggest total cross sectional area of each knot on its central axis. $A_{\text {total }}$ is the cross section of the board. In these equations, $\sigma_{\text {avg }}$ is the average stress and $\mathrm{A}_{\text {projected }}$ is the biggest projected knot surface in the window on the cross section (Khaloian and Van de Kuilen 2019a, b).

\begin{tabular}{|c|c|c|c|c|c|c|c|c|c|}
\hline \multirow[t]{2}{*}{ Species } & \multirow[t]{2}{*}{ PK } & \multicolumn{2}{|c|}{ Length (mm) } & \multicolumn{2}{|c|}{ Thickness (mm) } & \multicolumn{2}{|c|}{ Width (mm) } & \multicolumn{2}{|c|}{ Strength (Mpa) } \\
\hline & & Avg & $\mathrm{CoV}$ & Avg & $\mathrm{CoV}$ & Avg & $\mathrm{CoV}$ & Avg & $\mathrm{CoV}$ \\
\hline \multicolumn{10}{|l|}{ Beech } \\
\hline Beech $_{1}$ & 100 & 3102 & 0.003 & 24 & 0.01 & 151 & 0.003 & 31 & 0.43 \\
\hline Beech $_{2}$ & 100 & 3102 & 0.002 & 24 & 0.01 & 100 & 0.002 & 34 & 0.44 \\
\hline \multirow[t]{2}{*}{ Species } & \multirow[t]{2}{*}{ PK } & \multicolumn{2}{|c|}{ Density $\left(\mathrm{Kg} / \mathrm{m}^{3}\right)$} & \multicolumn{2}{|c|}{$\mathrm{MoE}_{\text {static }}(\mathrm{MPa})$} & \multicolumn{2}{|c|}{ DEB (-) } & \multicolumn{2}{|c|}{$\mathrm{DAB}(-)$} \\
\hline & & Avg & $\mathrm{CoV}$ & Avg & $\mathrm{CoV}$ & Avg & $\mathrm{CoV}$ & Avg & $\mathrm{CoV}$ \\
\hline \multicolumn{10}{|l|}{ Beech } \\
\hline Beech $_{1}$ & 100 & 758 & 0.05 & 11,100 & 0.18 & 0.18 & 0.55 & 0.20 & 0.61 \\
\hline Beech $_{2}$ & 100 & 773 & 0.05 & 11,300 & 0.24 & 0.21 & 0.55 & 0.24 & 0.59 \\
\hline
\end{tabular}

Table 1 Material and mechanical properties of the boards used for the simulations 
Dynamic MoE was numerically calculated by performing the stress-wave analysis for each board. Velocity of the wave was calculated after one complete travel of the wave in the board forth and back. Based on the velocity of the stress wave, the frequency and correspondingly the dynamic MoE was calculated (Khaloian and Van de Kuilen 2019c). To reduce the dependency of the numerical simulations on the input parameters, the average density of beech samples $\left(\rho=760 \mathrm{~kg} / \mathrm{m}^{3}\right)$ was used as an input parameter for the density.

To predict the tensile strength of the boards, the identifying parameters from experiments and measurements (presented as test results) as well as the numerical parameters (presented as simulation results) were used in linear and non-linear multiple regression analyses.

\subsection{Log and board reconstruction}

For estimation of the yield, the geometrical model of the logs was reconstructed in the first step of this study. This process was done based on the point clouds obtained from laser scanning of the logs. An example of a geometrical configuration of a beech log with frequent curvatures is presented in Fig. 2. It is qualitatively shown in this figure that for the $\log$ s with frequent curvatures, the yield might be strongly influenced by the shape of the logs, especially when the length of the boards is the point of interest. This condition is shown by multiple circles over the cross section of a $\log$, representing the frequent curvatures in Fig. 2.

In contrast to the log shown in Fig. 2 with multiple circles over the cross-section, a straight log may have a more uniform geometrical shape. In a straight log, the cross section may have a single circular shape. This may ease the conditions for cutting longer and straight boards.

For reconstruction of the logs, surface normals were approximated first. Second, a triangular mesh was reconstructed for each three points of the point clouds in a triangular configuration, to generate a surface. To do this,
Poisson Surface Reconstruction (Kazhdan et al. 2006) and Ball-Pivoting methods (Bernardini et al. 1999) were used. Put simply, for each triangle of points, a surface was approximated to reconstruct the full surface of the log from the point clouds. Dense point region (from laser scanning) was given the opportunity for the reconstruction of the curved and non-smooth surfaces in this case, as smaller triangles could be created by connecting these points.

Poisson reconstruction is a global solution that considers the complete set of cloud data at once, in contrast to many implicit surface fitting methods that are using data segmentation, local fitting and then blending for combining the results (Kazhdan et al. 2006). Thus, smooth surfaces can be created by using the Poisson reconstruction method, which helps to approximate the noisy data robustly (Kazhdan et al. 2006).

By combining the points obtained from the laser scanning, and after interpolating the given point cloud, Ball Pivoting algorithm was used for computing a triangle mesh for the structure. The principle of this method is that a ball of a user-specified radius, $\rho$, pivots between the points and if it touches the three points without containing any other point, these three points form a triangle. Therefore, in this method, the edges were constructed by pivoting the ball from one sample point to the other. This process was done until the complete set of the scanned points was considered (Bernardini et al. 1999). By selecting a too low sampling density of the points, some of the edges may not be created, which may cause formation of holes in the reconstructed structure.

The log reconstruction process of this study as well as the required file formats during this process are presented in Fig. 3.

Virtual cutting process in this study was done solely by considering the curvature and outer geometry of the logs, without considering the effects of the internal features on the quality of the boards (invisible from the point clouds); i.e. the outermost points on the log surface were considered as boundaries that were limiting the cutting pattern.
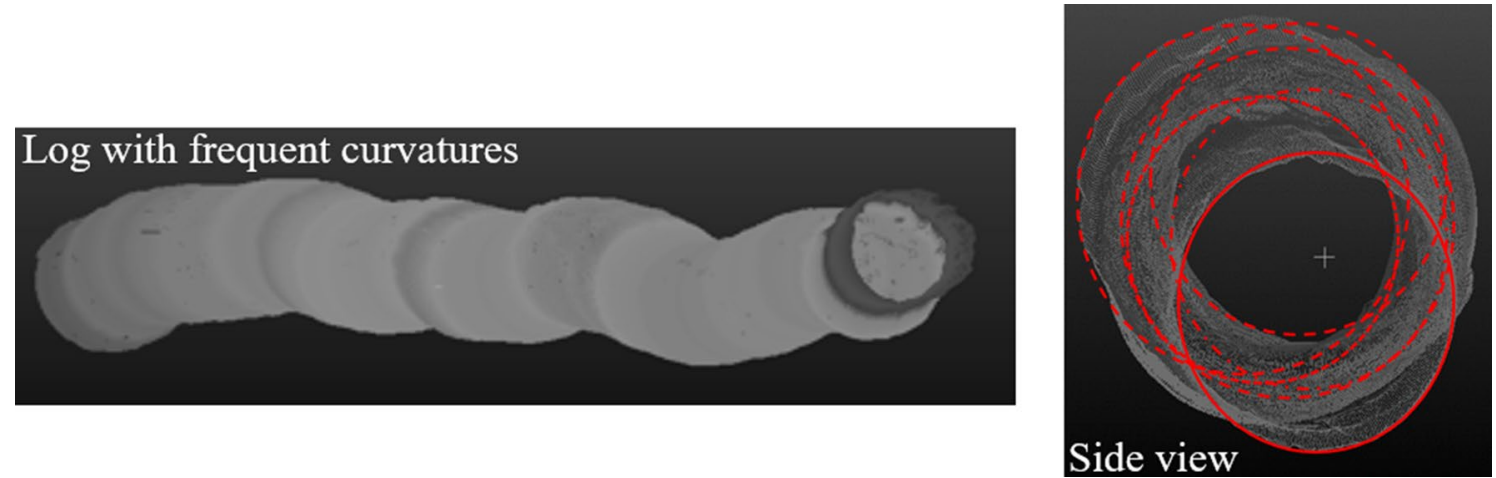

Fig. 2 Frequent curvatures of a beech $\log$ (the circles in the side view of this sample should help to follow the curvatures) 
Fig. 3 Flowchart, showing the process of the log reconstruction

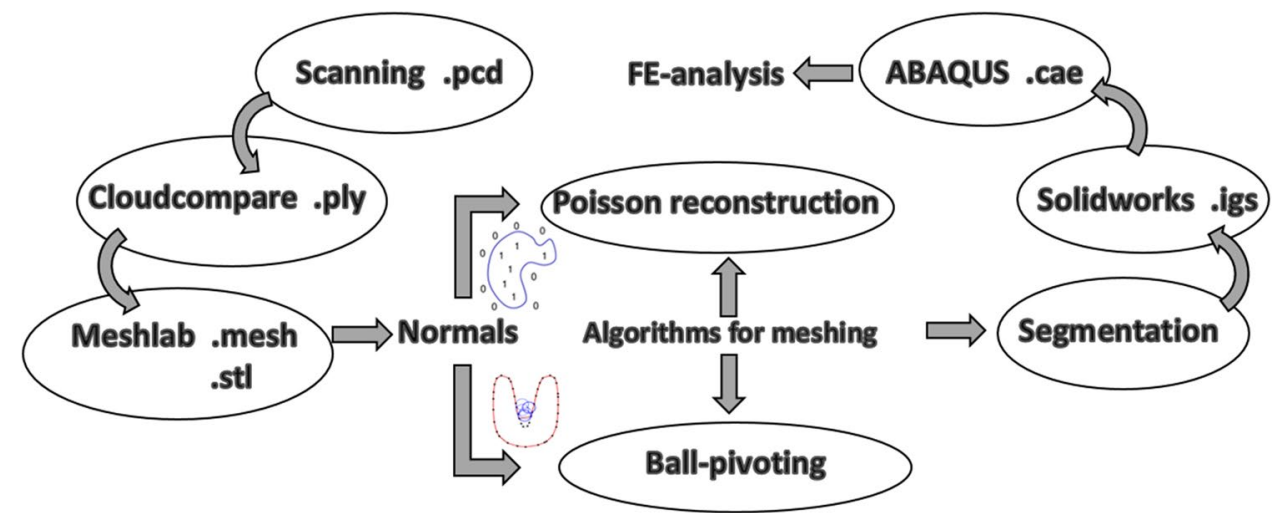

Information about the bark (thickness), the defects, etc. was not extractable from the point clouds. Due to the geometrical configuration of beech logs, different cutting patterns needed to be taken into account to optimize the yield, which included, in particular, the length and the width effects. Therefore, an unstructured mesh was initially created by considering all different cutting configurations. Then, the unnecessary cuts were deleted to come to the optimized predictions (Fig. 4). These deleted cuts were especially the ones that were partly located outside of the log boundary due to the strong curvature of the log. Therefore, these cuts were not contributing to the yield of the log.

In the second step of this study, which concentrated on board reconstruction and tensile strength prediction, a comprehensive 3D model of the boards was created based on the visible surface information of the knots. In visual grading, an assessment is made of the knots visible on the wood surface. To study the efficiency of such grading procedures, the Wood Research Institute of the Technical University of Munich has a database available with such surface information of a total of 20.000 boards, comprising both softwoods as well as medium dense hardwoods, including beech. By defining an automatic link to the surface data of the knots registered in the database, the boards were geometrically reconstructed with $3 \mathrm{D}$ representation of the knots. To reduce the possible measurement errors, an additional error term of $\pm 5(\mathrm{~mm})$ was added to the program for extraction of the coordinate direction and calculation of the angle of rotation of knots (Khaloian and Van de Kuilen 2019b). For each knot, a separate axis of rotation and plane was defined to represent the 3D geometry of the knots based on the location of the pith. The reconstructed surface of the log, the generated mesh, considering different board configurations with different dimensions and finally, the reconstructed board are presented in Fig. 4. It is shown that if the CT-scan is used for scanning of the $\log \mathrm{s}$, the reconstruction from $\log$ to boards can be done almost automatically (Rais et al. 2017). Laser scanning in this study provided the surface information of the logs, thus the information about the boards cannot be extracted directly from the logs. Therefore, this process is done in two steps here (as explained before).

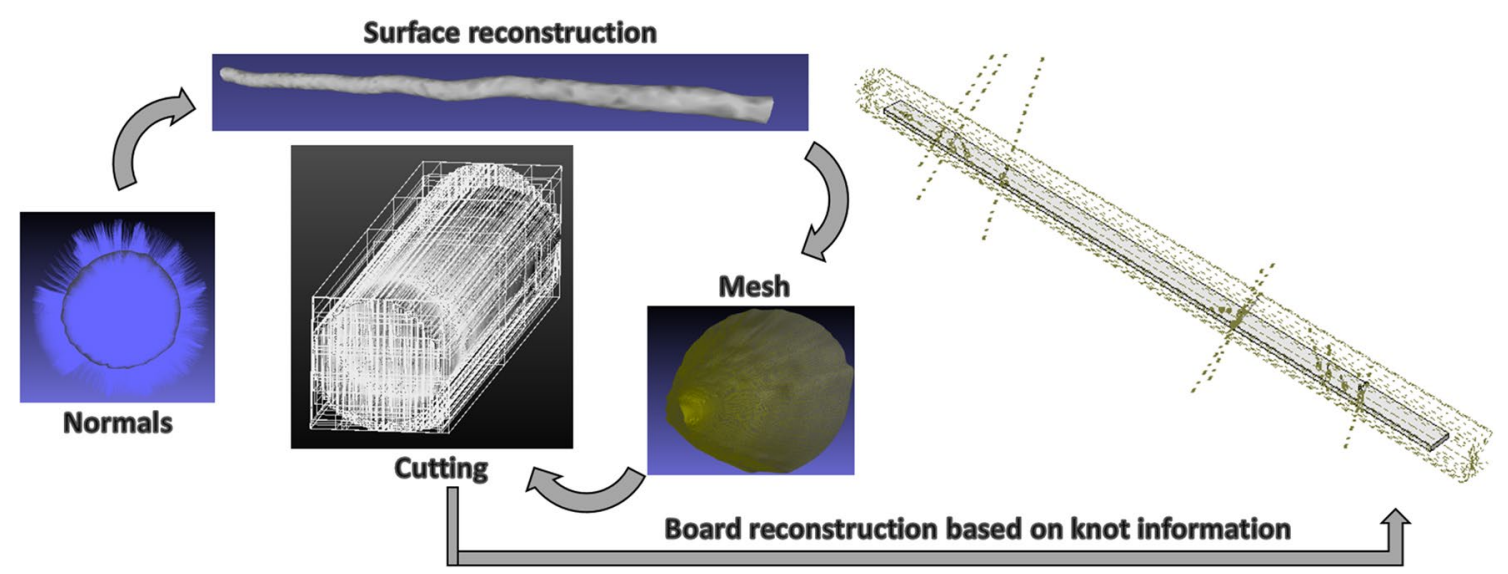

Fig. 4 Surface reconstruction, mesh generation, cutting pattern and board reconstruction with knots 


\subsection{Case analysis for logs and yield}

Validation of the numerical procedure was performed in this step of the analysis. Beech logs were chosen randomly from a mixture of beech-pine and beech-Douglas fir stands. The cutting pattern was optimized for a maximum of $50 \times 150 \times 4000 \mathrm{~mm}^{2}$ center-boards and $40 \times 80 \times 4000 \mathrm{~mm}^{3}$ boards from the outer parts of the logs. Similar cutting pattern was implemented for the numerical analysis. Saw thickness of $5 \mathrm{~mm}$ was considered in sawmills, which was also implemented numerically.

To analyze the sensitivity of the model to geometrical variations, four different configurations were considered here for the reference samples, and the results were compared to the actual values from sawmills and integrated for virtual cutting patterns. These four configurations were as follows:

- Case 1: If only boards of small dimensions $\left(40 \times 80 \mathrm{~mm}^{2}\right.$ cross-section) were extracted from the logs.

- Case 2: If only boards of large dimensions $\left(50 \times 150 \mathrm{~mm}^{2}\right.$ cross-section) were extracted from the logs.

- Case 3: If many boards were extracted from the logs, regardless of the dimensional aspects. Therefore, it was possible to extract more boards of smaller dimensions and fewer boards of larger dimensions. In this case, the cutting pattern was not optimized for center-boards with larger dimensions.

- Case 4: Similar to the real/actual condition in the sawmills, to optimize the cutting pattern for as many centerboards of larger dimension as possible and for smaller boards from the rest of the log volume.

Each of the above mentioned cases was analyzed separately and compared to the actual condition, which was a case similar to the Case 4 configuration. An example of these cases is schematically shown in Fig. 5.

The validated model was then used for virtual cutting to analyze 27 different dimensional variations of the board (shown in Table 2) and to analyze the effects of frequent curvatures of the logs on the yield. Similarly, a sawing thickness of $5 \mathrm{~mm}$ was implemented for this set of simulations as well.

By knowing the actual log volume in each case (for each $\log$ ), the yield ( $k$ : in percent) was calculated using the following equation:

$k=\left(\frac{V_{\text {boards }}}{V_{\text {real } \_ \text {log }}}\right) \times 100$

where $V_{\text {board }}$ is the total volume of the extracted boards from the $\log$, and $V_{\text {real_log }}$ is the total volume of the log.

By calculating the yield of the log in percent, the volume loss of the log can be calculated as 100-k, showing the amount of the volume of the log that is lost after cutting the boards.

\section{Results and discussion}

\subsection{Virtual cutting and dimensional effects}

For the actual case as well as for the four virtual cases (mentioned above), the percentage of the log volume loss was calculated and compared (Table 3). This comparison was to show the outcome of the sawmills (a case similar to Case 4) compared to the outcome of the simulations. It was shown that by using the Case 1 and Case 2 models, which were considered the extreme limit conditions, volume loss

Table 2 Dimensions of the boards

\begin{tabular}{|c|c|c|c|}
\hline & $\begin{array}{c}\text { Thickness } \\
\text { (mm) }\end{array}$ & $\begin{array}{l}\text { Width } \\
\text { (mm) }\end{array}$ & $\begin{array}{c}\text { Length } \\
\text { (mm) }\end{array}$ \\
\hline \multirow{3}{*}{ Log } & 20 & & 2000 \\
\hline & 25 & & 3000 \\
\hline & 30 & 160 & 4000 \\
\hline
\end{tabular}
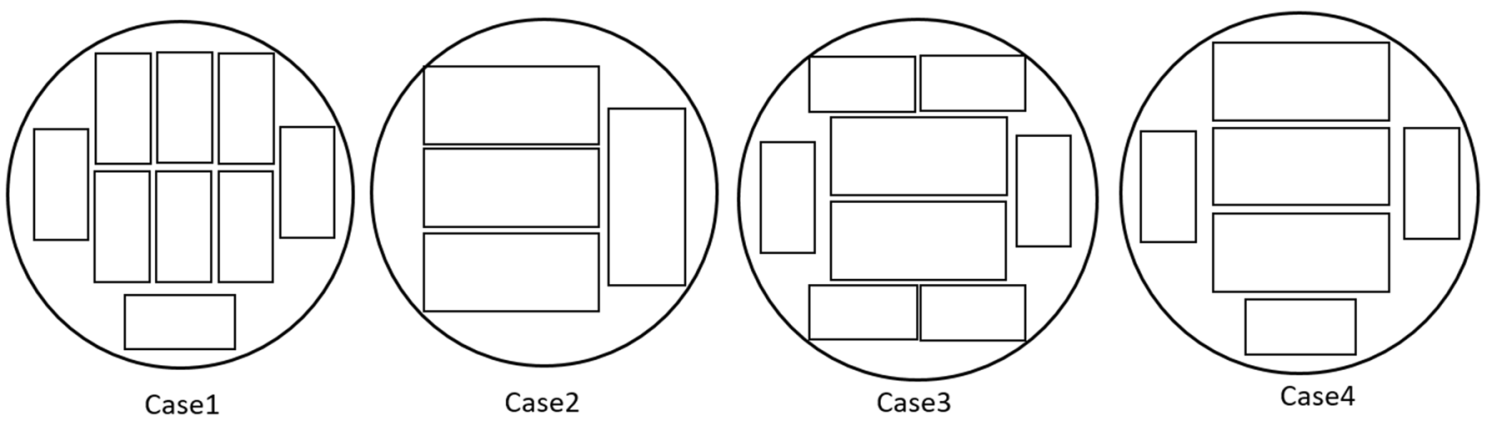

Fig. 5 Schematic example showing the case studies of cutting the logs into boards of $40 \times 80$ and/or $50 \times 150 \mathrm{~mm}^{2}$ (Case 3 considers more boards with smaller cross sections to handle the curvature effects along the length of the log) 
Table 3 Comparison of yield and volume loss for the actual and the four virtual cases

\begin{tabular}{llllll}
\hline Yield & Case 1 & Case 2 & Case 3 & Case 4 & Actual yield \\
\hline Volume loss (\%) & 50 & 53 & 45 & 44 & 54 \\
$\begin{array}{l}\text { Avg. yield (\%) } \\
\begin{array}{l}\% \text { of increase com- } \\
\text { pared to actual }\end{array}\end{array}$ & 7.6 & 0.9 & 17 & 19.5 & \\
yield & & & & & \\
\hline
\end{tabular}

is increasing. However, Case 3 and Case 4 models are relatively close to each other for predicting the yield and the volume loss. The difference between Case 4 model and the actual case may not only be due to the developed cutting pattern, but also due to considering the outermost points (from laser scanning) as surface of the logs for simulations and neglecting the bark influence in contrast to the actual case.

The $k$ value (presented in Eq. 3) was calculated for the four mentioned cases (where the dimensions of the boards, especially in the cross section, were varied) as well as the actual case of the sawn boards. By considering the average percentage of $k$, the yield by Case 1 model increased by 7.6\% compared to the actual case; Case 2, Case 3 and Case 4 by $0.9 \%, 17 \%$ and $19.5 \%$, respectively. This shows that Case 2 model with only large boards has the lowest yield. However, by optimizing the cutting pattern, an increase in yield of, in total, $19.5 \%$ can be expected, neglecting the quality of the boards. As mentioned before, this increase may be due to the lack of information about the quality of the log, the location of bark, knots and defects, location of the pith and correspondingly, consideration of the outermost points of the logs for the analysis. Therefore, as virtual board extraction was done based on the maximum volume of the logs, the yield may be slightly overestimated numerically. A comparison between the virtual $k$ value of each case and the actual (total) $\log$ volume is presented in Fig. 6 .

The coefficient of determination, when relating $k$ and $V_{\text {real_log }}$ in the actual case is $\mathrm{R}^{2}=0.58$ (shown in Fig. 6). By performing the virtual analysis, this relation is higher for Case 4 compared to Case3, Case2 or Case1. This is due to the reduction in the total volume of boards extracted from the logs, when comparing Case 4 to Case 1 .

By correlating the yield of each of the four cases to the actual yield of the $\log (Y=k / 100)$, Case 4 is found to be the optimized condition, with higher $\mathrm{R}^{2}$ value (presented in Fig. 6).

The correlation is much lower in Case 1 and Case 2 models. This confirms that an optimum mixture of the smalland large-sized boards needs to be considered to be able to increase the yield.

In the next step, length effect of boards on yield is analyzed. Therefore, boards with lengths of 2,3 , and $4 \mathrm{~m}$ are virtually cut from $4.1 \mathrm{~m}$ long logs. The number of boards, in case of cutting directly $4 \mathrm{~m}$ long boards and dividing them into half, or cutting directly $2 \mathrm{~m}$ long boards from the log, was analyzed. This case was checked for the boards with
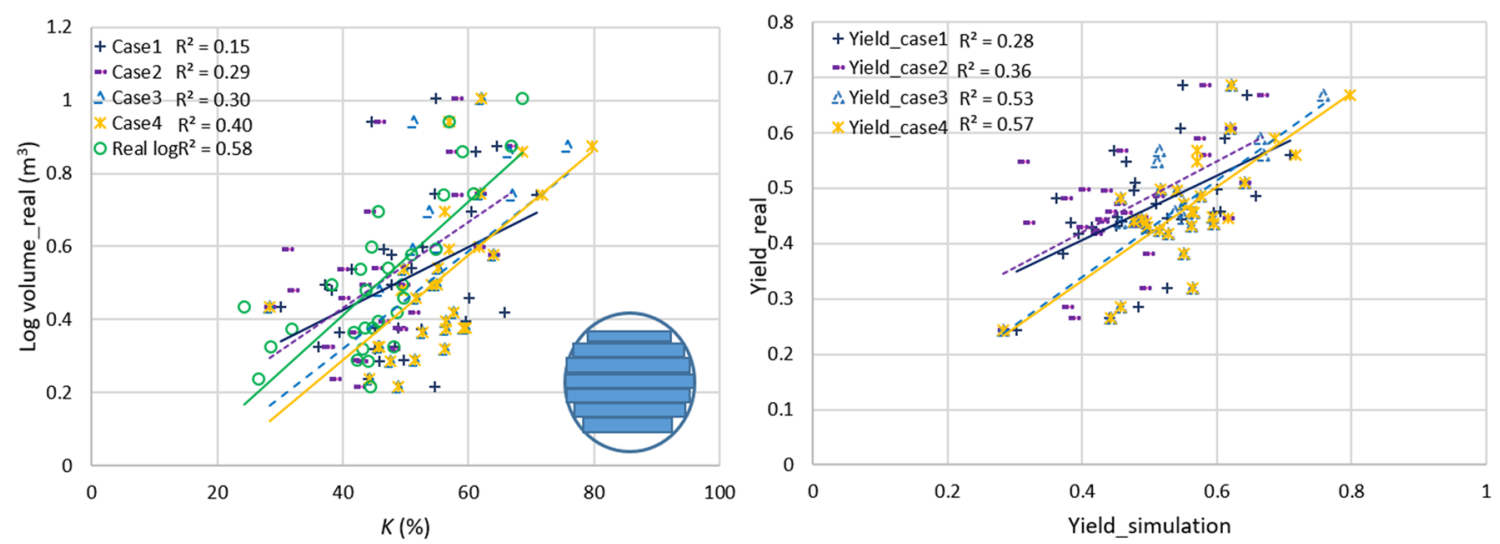

\begin{tabular}{|c|c|c|c|c|c|c|c|}
\hline \multicolumn{9}{|c|}{ y=ax+b } \\
\hline Log $_{\text {volume-k }}$ & $\mathbf{a}$ & $\mathbf{b}$ & $\mathbf{R}^{\mathbf{2}}$ & Yield $_{\text {real-Yield }}$ simulation & $\mathbf{a}$ & $\mathbf{b}$ & $\mathbf{R}^{\mathbf{2}}$ \\
\hline Case1 & 0.009 & 0.08 & 0.15 & Case1 & 0.583 & 0.17 & 0.28 \\
\hline Case2 & 0.012 & -0.04 & 0.29 & Case2 & 0.637 & 0.17 & 0.34 \\
\hline Case3 & 0.013 & -0.21 & 0.30 & Case3 & 0.873 & -0.01 & 0.53 \\
\hline Case4 & 0.014 & -0.28 & 0.40 & Case4 & 0.85 & -0.01 & 0.57 \\
\hline Real log & 0.016 & -0.21 & 0.58 & & & \\
\end{tabular}

Fig. 6 Relation between actual and virtual log volumes and yield $(k)$. Constants $(\mathrm{a}, \mathrm{b})$ of the linear correlations and the resulting $\mathrm{R}^{2}$ values are shown in the table below each figure 
20, 25, $30 \mathrm{~mm}$ thickness and 80,120, and $160 \mathrm{~mm}$ width, respectively. The results, regarding the changes in the total number of the boards and respectively the volume of the boards are shown in Fig. 7. To show how the length of the boards may influence the volume and the yield, a schematic presentation of the cutting is provided in Fig. 7 for both straight and curved logs. Similar analyses were performed to figure out the width effects (for the boards of $80 \mathrm{~mm}$ or $160 \mathrm{~mm}=2 * 80 \mathrm{~mm}$ width). Comparisons of the changes in yield and number of boards in case of dimensional changes are presented in Table 4. It is shown that among the coordinate dimensions of the beech boards, length has the main influence on the yield of the logs. This is due to the strong curvatures and geometrical non-uniformities of beech logs. Therefore, cutting shorter boards $(2 \mathrm{~m})$ in comparison to longer ones $(4 \mathrm{~m})$ results in a $15 \%$ increase in yield. Difference between the number of the boards in the case of cutting $3 \mathrm{~m}$ or $4 \mathrm{~m}$ is small, sometimes even zero, depending on the curvature of the log. The total volume of the boards can consequently be smaller, because of the difference in length. Therefore, the yield is also influenced and may be higher in case of sawing $4 \mathrm{~m}$ boards compared to $3 \mathrm{~m}$. It also needs to be mentioned that the total length of the logs considered here is $4.1 \mathrm{~m}$. The outcome depends on the original length and shape/curvature of the logs and the required cross-sections/ length of the boards. As explained in Table 2, lengths of $2 \mathrm{~m}$, $3 \mathrm{~m}$, and $4 \mathrm{~m}$ were considered in this study based on $4.1 \mathrm{~m}$ logs. A length of $2 \mathrm{~m}$ covers the strong frequent curvatures in this case. Therefore, it is assumed that cutting shorter than $2 \mathrm{~m}$ boards (e.g. $1 \mathrm{~m}$ long) will not/slightly increase the
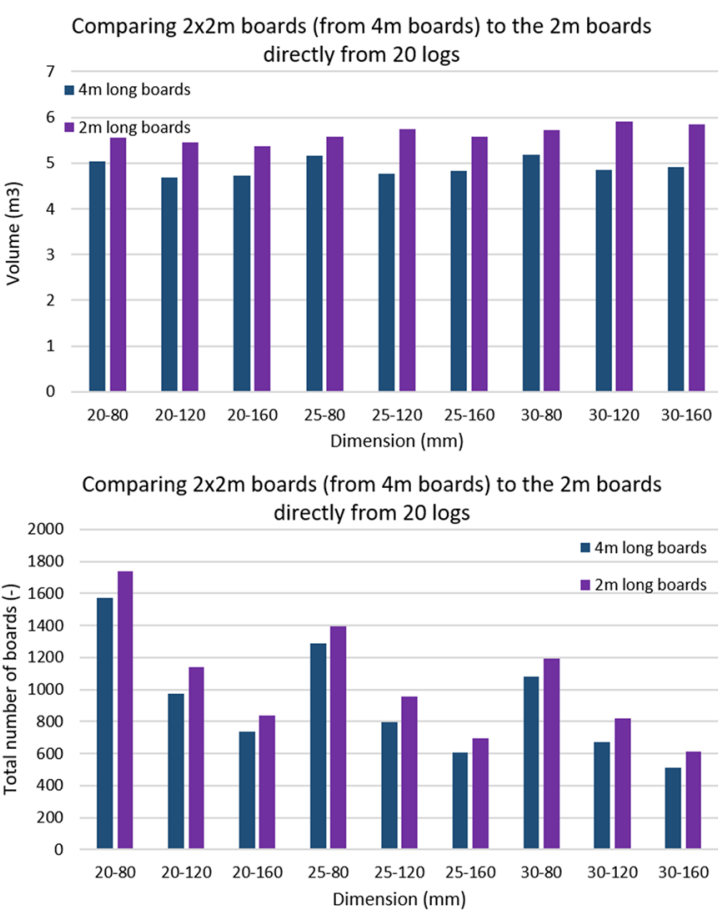

a)

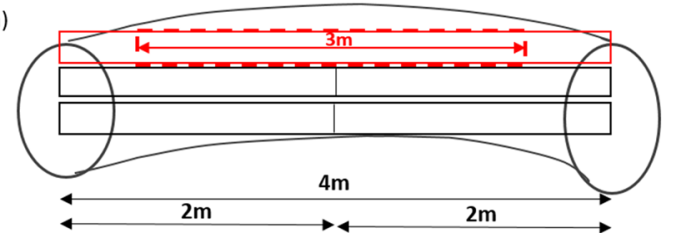

Comparing $(2 \times 80) \mathrm{mm}$ board width to the $80 \mathrm{~mm}$ wide boards from 20 logs directly

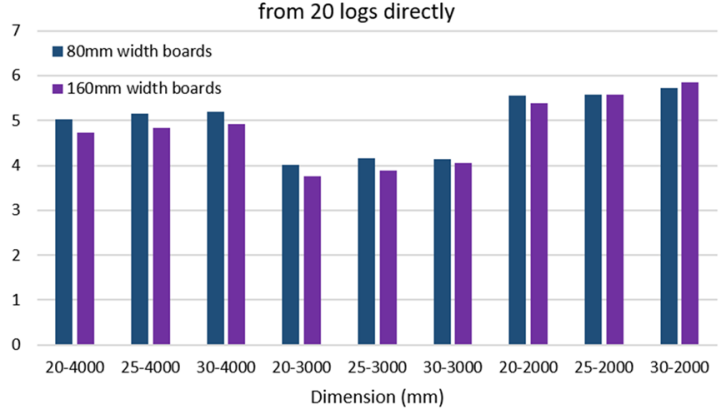

Comparing $(2 \times 80) \mathrm{mm}$ board width to the $80 \mathrm{~mm}$ wide boards from 20 logs directly

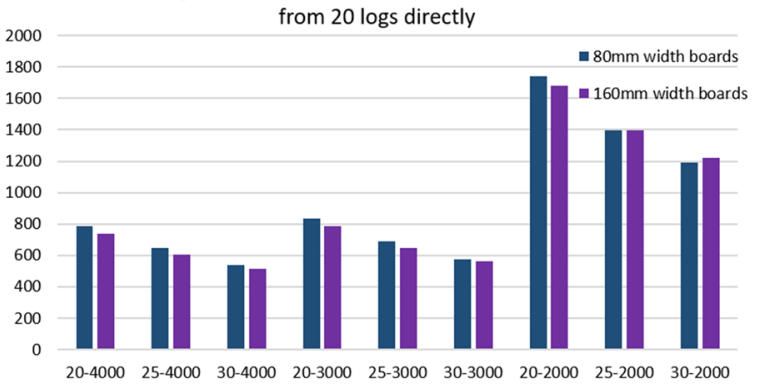
Dimension (mm)

b)

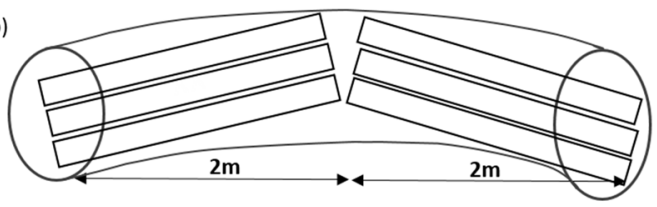

c)

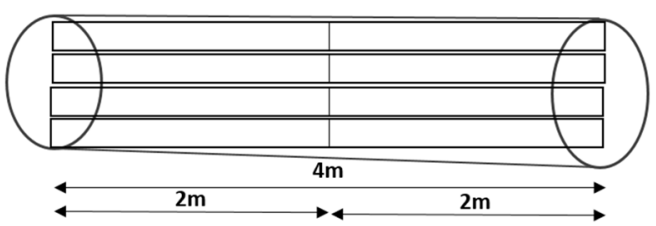

Fig. 7 Comparison between $2 \mathrm{~m}$ and $2 \times 2 \mathrm{~m}$ boards as well as $80 \mathrm{~mm}$ and $2 \times 80 \mathrm{~mm}$ wide boards regarding the total number and volume of the boards in each case. a, b Example log with exaggerated curvature and cutting pattern, $\mathbf{c}$ schematic view of an example of a straight log 
Table 4 Influence of board size on total volume and number of the boards in 20 measured logs

\begin{tabular}{lll}
\hline Dimensions $(\mathrm{mm})$ & $\begin{array}{l}\text { Variation of average } \\
\text { board number }(\%)\end{array}$ & $\begin{array}{l}\text { Variation of aver- } \\
\text { age board volume } \\
(\%)\end{array}$ \\
\hline Width $(\mathrm{mm})$ & & \\
$120 \longrightarrow>80$ & 52 & 1.6 \\
$160 \longrightarrow>80$ & 108 & 3.6 \\
$160 \longrightarrow>120$ & 36 & 2.1 \\
Thickness (mm) & & \\
$25 \longrightarrow>20$ & 22 & -2.7 \\
$30 \longrightarrow>25$ & 17 & -2.5 \\
$30 \longrightarrow>20$ & 42 & -5.1 \\
Length $(\mathrm{mm})$ & & \\
$4000 \longrightarrow>3000$ & 10 & -17.3 \\
$3000->2000$ & 109 & 39.2 \\
$4000 \longrightarrow>2000$ & 130 & 15.1 \\
\hline
\end{tabular}

yield. However, the board width does not have a considerable effect on the volume and the yield. By comparing the total number of the boards with a width of $80 \mathrm{~mm}$ to the ones with a width of $160 \mathrm{~mm}=2 \times 80 \mathrm{~mm}$, an increase of $3.6 \%$ is obtained, when cutting smaller boards.

As the thicknesses of 20,25 , and $30 \mathrm{~mm}$ were considered in this study, it is difficult to draw a clear conclusion on the influence of the thickness of the boards on the yield of the material. However, as generally a mixed cutting pattern is used (similar to the logs in this study, where cutting pattern is optimized for center-boards with larger dimensions and side-boards with smaller dimensions), an assumption can be made that the thickness of the boards, similar to the width effects, does not have a significant influence on the yield of the material. This condition is shown in Table 4 for the number and volume of the boards. Although cutting thinner boards with smaller width increases the number of the boards, as shown in this figure, the effect on the volume and the yield is much smaller compared to the length effect. For each specific size of each dimension, nine different dimensional variations were considered and the average of the results was used for comparisons. As an example, for boards with a thickness of $20 \mathrm{~mm}$ (which is used only for virtual cutting), these different dimensional configurations are presented in Table 5.

Similarly, different dimensional variations were considered for each of the other cases. It is shown that the dimensional effects can be neglected in straight logs in contrast to the $\log$ s with curvatures. 


\subsection{Virtual strength prediction}

By running the numerical analysis for 194 lower quality beech boards with strong fiber deviations, it is shown that due to the strong geometrical complexity of beech boards, $\mathrm{MoE}_{\text {dyn }}$ is not sufficient as a single parameter for strength predictions $\left(R^{2}=0.5\right.$ compared to $R^{2}=0.4$ for tests and simulations, respectively). This means that to get higher accuracy in the quality of the strength prediction, other parameters than the virtual dynamic MoE need to be considered for the predictions. Therefore, knot parameters, their geometrical representations and their effects on distribution of the stresses are also playing an important role for strength prediction of the lower quality boards.

When comparing the relationship of only simulated knot parameters based on the stress developments under tensile loading $\left(\mathrm{SCF}_{1}, \mathrm{SCF}_{2}\right.$ and $\left.\mathrm{SCF}_{3}\right)$ with measured tensile strength to the relationship of the measured knot parameters from visual grading (DEB, DAB) with the measured tensile strength in a linear multiple regression analysis, significant improvements are seen in the quality of the predictions based on the numerical parameters $\left(R^{2}=0.56\right.$ compared to $\mathrm{R}^{2}=0.18$ ).

By performing a nonlinear multiple regression analysis between the numerical and test parameters with the tensile strength, mathematical Eq. 4 is given. $f=\sum_{i=1}^{n} a_{i} \cdot e^{b_{i} \cdot S C F_{i}}+c \cdot M o E_{d y n}+d$

where $n$ is the number of the SCFs required for the strength predictions, $\mathrm{SCF}_{\mathrm{i}}$ are the stress concentration factors, presented above. The parameter $f$ is the tensile strength, $M o E_{d y n}$ is the dynamic modulus of elasticity, and $a, b, c, d, e$ are the constants, provided in Table 6 . Figure 8 shows this nonlinear multiple regression analysis graphically.

Additionally, a comparison between the numerical and experimental parameters and the tensile strength is presented in Fig. 8.

By considering the geometrical effects of the knots on the tensile strength of the boards in the numerical simulations, the predictions improve considerably. However, for the low-quality boards in this study, usage of only two stress concentration factors in combination with the numerical $\mathrm{MoE}_{\mathrm{dyn}}$ (by application of the average density) for multiple regression analysis is sufficient for the prediction of the tensile strength $\left(R^{2}=0.58\right.$ presented in Fig. 8). Addition of the third SCF does not improve the quality of the predictions to more than $10 \%\left(\mathrm{R}^{2}=0.59\right.$ compared to $\mathrm{R}^{2}=0.58$ ). Therefore, this parameter is not considered as an extra parameter for the tensile strength predictions.

Table 6 Coefficients of Eq. 4 for tensile strength predictions

\begin{tabular}{lllllll}
\hline & $\mathrm{a}_{1}$ & $\mathrm{a}_{2}$ & $\mathrm{~b}_{1}$ & $\mathrm{~b}_{2}$ & $\mathrm{c}$ & $\mathrm{d}$ \\
\hline$f$ & -15.89 & -35.35 & 0.11 & 0.21 & 0.0024 & 73.24 \\
\hline
\end{tabular}
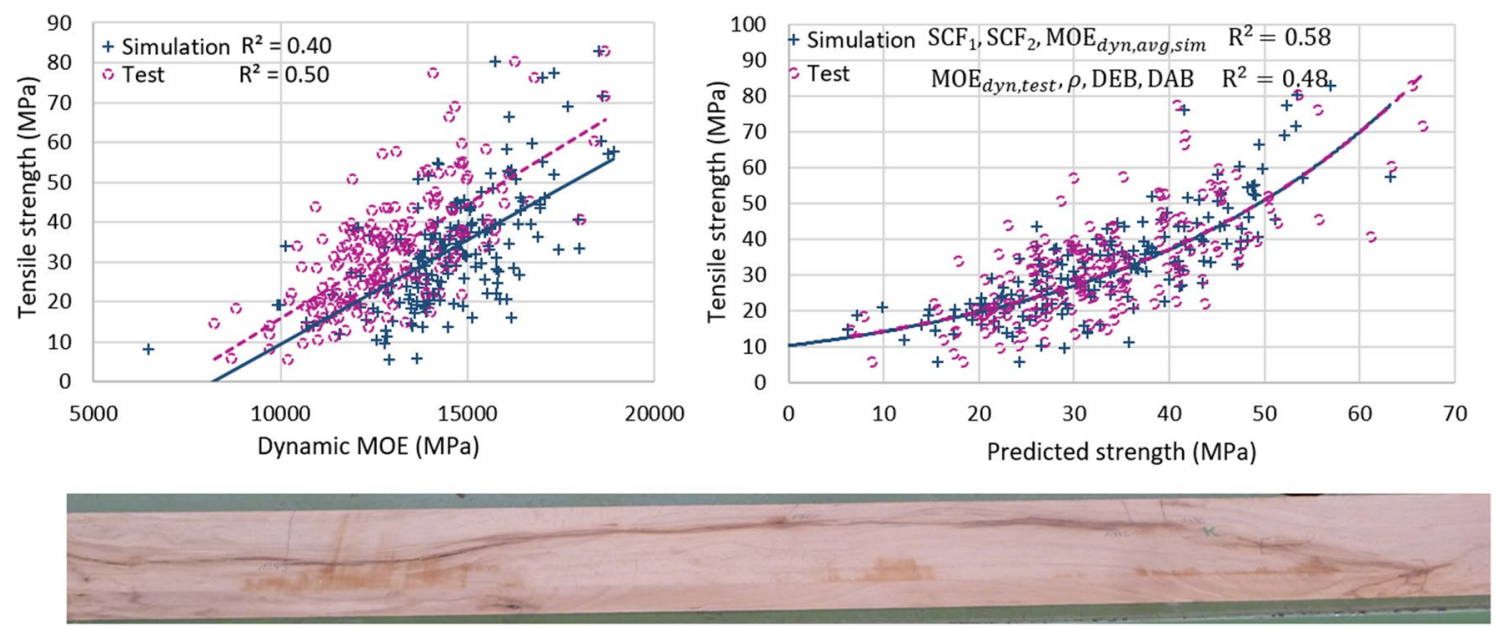

Fig. 8 Comparison of the tested and simulated parameters to the measured tensile strength and an example of beech board with extreme fiber deviation. (Left: simulated vs. actual dynamic MoE, right: predicted vs. actual tensile strength of the boards) 


\section{Conclusion}

Two yield-influencing processing steps were analysed in this study: the influence of dimensional variations of boards and board length on the yield of the log, and the strength prediction of 194 low-quality beech boards.

- Due to more frequent curvatures in beech logs as compared to softwoods, an optimum configuration needs to be defined to be able to increase the yield as much as possible. In this study, by considering the outermost points of the beech logs from observed point clouds for the reconstruction of the logs, and without considering the quality of the extracted boards, an increase of about $15 \%$ in the yield of the logs is expected by cutting shorter boards. It is shown that the width and thickness effects can be neglected, due to their small influence $(3.6 \%$ increase) on the yield. Additionally, the dimensional effects can be neglected in very straight logs. Therefore, length effects need to be considered in the cases of logs with curvatures.

- For strength prediction of low-quality beech boards with strong fiber deviations, it is shown that an accurate consideration of the knot geometries has a considerable influence on the prediction of the tensile strength, beside the numerically simulated $\mathrm{MoE}_{\mathrm{dyn}}$, when applying the average density of the specimen. It is shown that multiple regression analysis using the numerically extracted parameters with the tensile strength gives a higher coefficient of determination than the one with the measured parameters in the laboratory. Numerical parameters include two stress concentration factors and the simulated $\mathrm{MoE}_{\mathrm{dyn}}$. Measurement parameters are the knot parameters (DEB and DAB according to DIN 4074) in combination with the measured $\mathrm{MoE}_{\text {dyn }}$. The $\mathrm{R}^{2}=0.58$ compared to $\mathrm{R}^{2}=0.48$ for the simulations and the tests show the potential of the developed method for tensile strength predictions. This method is only based on visual surface information of knots.

As every board needs to be strength-graded before it is used in structural applications, the provided method can be used for estimation of the tensile strength beside the visual or machine grading methods.

Acknowledgements Open Access funding provided by Projekt DEAL. The authors gratefully acknowledge the support of the Bayerische Landesanstalt für Wald und Forstwirtschaft for funding the project X042"Beechconnect" which allowed for the work presented in this paper.

\section{Compliance with ethical standards}

Conflict of interest On behalf of all authors, the corresponding author states that there is no conflict of interest.

Open Access This article is licensed under a Creative Commons Attribution 4.0 International License, which permits use, sharing, adaptation, distribution and reproduction in any medium or format, as long as you give appropriate credit to the original author(s) and the source, provide a link to the Creative Commons licence, and indicate if changes were made. The images or other third party material in this article are included in the article's Creative Commons licence, unless indicated otherwise in a credit line to the material. If material is not included in the article's Creative Commons licence and your intended use is not permitted by statutory regulation or exceeds the permitted use, you will need to obtain permission directly from the copyright holder. To view a copy of this licence, visit http://creativecommons.org/licenses/by/4.0/.

\section{References}

Baño V, Arriaga F, Soilán A, Guaita M (2010) F.E.M. analysis of the strength loss in timber due to the presence of knots. World Conference on Timber Engineering, Riva del Garda, Italy. ISBN: 978-88-901660-3-7

Bernardini F, Mittleman J, Rushmeier H, Silva C, Taubin G (1999) The ball-pivoting algorithm for surface reconstruction. IEEE Trans Visual Comput Graphics 5(4):349-359. https://doi. org/10.1109/2945.817351

Bhandarkar SM, Luo X, Daniels R, Tollner EW (2006) A novel featurebased tracking approach to the detection, localization, and 3-D reconstruction of internal defects in hardwood logs using computer tomography. Pattern Anal Appl 9:155-175. https:// doi.org/10.1007/s10044-006-0035-9

Boukadida H, Longuetaud F, Colin F, Freyburger C, Constant T, Leban JM, Mothe F (2012) PithExtract: a robust algorithm for pith detection in computer tomography images of wood-application to $125 \operatorname{logs}$ from 17 tree species. Comput Electron Agric 85:90-98. https://doi.org/10.1016/j.compag.2012.03.012

Cramer SM, Goodman JR (1986) Failure modeling: a basis for strength prediction of lumber. Wood Fiber Sci 18:446-459

DIN 4074 (2012) Strength grading of wood-Part 1: Coniferous sawn timber. German Institute for Standardization

EN 408 (2010) Timber structures-structural timber and glued laminated timber-determination of some physical and mechanical properties. CEN, Brussels

Foley C (2001) A three-dimensional paradigm of fibre orientation in timber. Wood Sci Technol 35:453-465

Goodman JR, Bodig J (1978) Mathematical model of the tension behavior of wood with knots and cross grain. In: Proc First Int Conf On Wood Fracture, Banff

Goodman JR, Bodig J (1980) Tension behavior of wood-an anisotropic, inhomogeneous material. Structural research report No. 32. Colorado State University, Fort Collins.

Hackspiel C, de Borst K, Lukacevic M (2014) A numerical simulation tool for wood grading model developement. Wood Sci Technol 48(3):633-649. https://doi.org/10.1007/s0022 6-014-0629-0

Jenkel C, Kaliske M (2013) Analyse von Holzbauteilen unter Berücksichtigung struktureller Inhomogenitäten (Analysis of timber components taking into account structural inhomogeneities). Bauingenieur 88:494-507 (In German) 
Kazhdan M, Bolitho M, Hoppe H (2006) Poisson Surface Reconstruction. Eurographics Symposium on Geometry Processing. pp 61-70

Khaloian A, Gard WF, van de Kuilen JWG (2017) 3D FE-numerical modelling of growth defects in medium dense European hardwoods. In: Proceedings of the sixth international scientific conference on hardwood processing, Lahti, pp 60-67

Khaloian-Sarnaghi A, van de Kuilen JWG (2019a) Strength prediction of timber boards using 3D FE-analysis. Constr Build Mater 202:563-573. https://doi.org/10.1016/j.conbuildmat.2019.01.032

Khaloian-Sarnaghi A, van de Kuilen JWG (2019b) An advanced virtual grading method for wood based on surface information of knots. Wood Sci Technol 53:535-557. https://doi.org/10.1007/ s00226-019-01089-w

Khaloian-Sarnaghi A, van de Kuilen JWG (2019c) Tensile strength prediction of softwood glulam lamellas using virtual vibration technique. ASCE J Mater Civil Eng. https://doi.org/10.1061/ (ASCE)MT.1943-5533.0002936

Kovryga A, Khaloian Sarnaghi A, van de Kuilen J.W.G (2019) Strength grading of hardwoods using transversal ultrasound. Proceedings of the seventh international scientific conference on hardwood processing ISCHP, Delft, The Netherlands, pp 220-229

Longuetaud F, Leban JM, Mothe F, Kerrien E, Berger MO (2004) Automatic detection of pith on ct images of spruce logs. Comput Electr Agric 44:107-119

Longuetaud F, Mothe F, Kerautret B, Krähenbühl A, Hory L, Leban J, Debled-Rennesson I (2012) Automatic knot detection and measurements from x-ray ct images of wood: a review and validation of an improved algorithm on softwood samples. Comput Electron Agric 85:77-89
Lukacevic M, Füssl J (2014) Numerical simulation tool for wooden boards with a physically based approach to identify structural failure. Eur J Wood Prod 72:497-508

Phillips GE, Bodig J, Goodman JR (1981) Flow-grain Analogy. Wood Sci 14:55-65

Rais A, Ursella E, Vicario E et al (2017) The use of the first industrial X-ray CT scanner increases the lumber recovery value: case study on visually strength-graded Douglas-fir timber. Ann For Sci 74:28. https://doi.org/10.1007/s13595-017-0630-5

Rais A, Jacobs M, Khaloian A, Van de Kuilen J-WG, Pretzsch H (2018) Qualitätsorientiertes 3D-Scanning im Mischwald (Quality-orientated 3D scanning in mixed forests). Ammer C, Bredemeier M, Von Arnim G (eds) Forstwissenschaftliche Tagung 2018 Göttingen, 24 to 26 September 2018, p 446

Rais A, van de Kuilen JWG, Pretzsch H (2020) Impact of species mixture on the stiffness of beech (Fagus sylvatica L.) sawn timber. For Ecol Manage 461:117935. https://doi.org/10.1016/j.forec o.2020.117935

Steele P, Wagner F, Kumar L, Araman PA (1993) The value versus volume yield problem for live-sawn hardwood sawlogs. For Prod J 43:35-40

Publisher's Note Springer Nature remains neutral with regard to jurisdictional claims in published maps and institutional affiliations. 